\title{
Capitalismo, democracia econômica e princípio da diferença *
}

Leandro Martins Zanitelli ${ }^{\dagger}$

\section{RESUMO}

O trabalho procura verificar se Schweickart está correto ao afirmar que o tipo de regime institucional por ele defendido, a "democracia econômica” (uma versão de socialismo de mercado), deveria ser também o preferido dos rawlsianos. Argumenta-se no sentido de que há razão para acreditar que, comparada a regimes capitalistas, a democracia econômica eleve as expectativas dos cidadãos hipossuficientes quanto a alguns bens primários presumivelmente sujeitos ao princípio da diferença de Rawls, como o emprego, o lazer, o trabalho significativo e a democracia no trabalho. Tendo em vista, no entanto, que a democracia econômica também parece propensa a reduzir expectativas no que toca à riqueza e à renda, uma conclusão peremptória acerca da superioridade de um dos tipos de regime não parece possível.

Palavras-chave: Democracia Econômica. Princípio da Diferença. Capitalismo. Rawls.

\section{INTRODUÇÃO}

Na literatura recente sobre Rawls, um tema frequentemente tratado é o dos arranjos institucionais (ou tipos de regime institucional) mais propensos à realização dos princípios da justiça rawlsiana (a “justiça como equidade”). O próprio Rawls dispensou certa atenção a esse tema em suas obras, em particular em Justiça como Equidade: Uma Reformulação, na qual discorre mais longamente sobre um de seus tipos de regime preferidos, o da democracia de cidadãos proprietários (property-owning democracy) (RAWLS, 2001, parte IV).

Parte do debate tem girado em torno das características da democracia de cidadãos proprietários e das razões pelas quais esse tipo de regime é superior ao do estado de bem-estar (do qual Rawls foi, por certo tempo, tido como apologeta). São de referir, entre outros, os trabalhos reunidos em uma coletânea organizada por Martin O’Neill e Thad Williamson (O’NEILL e WILLIAMSON, 2012) e em um número especial da revista Analyse \& Kritik (2013). Em um desses trabalhos, David Schweickart (SCHWEICKART, 2012) argumenta em favor da superioridade de um tipo de regime de socialismo de mercado, a “democracia econômica”, frente aos regimes capitalistas em geral, entre os quais se inclui tanto o estado de bem-estar tradicional quanto a democracia de cidadãos proprietários de Rawls.

\footnotetext{
* Artigo recebido em 01/12/2014 e aceito em 30/05/2015.

${ }^{\dagger}$ Doutor em Direito pela Universidade Federal do Rio Grande do Sul, Professor da Universidade Federal de Minas Gerais, Brasil.
} 
O objetivo do presente trabalho é avaliar essa última afirmação. Tratar-se-á, todavia, de uma avaliação parcial, já que me limitarei a verificar se, à luz de um dos princípios da concepção de justiça de Rawls, o princípio da diferença, há, de fato, razão para apregoar a superioridade da democracia econômica sobre regimes capitalistas. Minha conclusão, quanto a isso, será mais cautelosa do que a de Schweickart. Argumentarei no sentido de que, embora, sob certas circunstâncias, a democracia econômica se mostre mais propensa do que o capitalismo a atender ao princípio da diferença, em outras o contrário é que pode ocorrer. É também possível, além disso, que versões dos dois tipos de regime sejam, por vezes, incomparáveis sob o princípio em questão. Quando isso ocorrer, a preocupação com a estabilidade pode desaconselhar um regime cujo "pacote" de bens primários esteja em forte desajuste com as preferências dos cidadãos.

A primeira parte do artigo faz alguns esclarecimentos e considerações metodológicas sobre a comparação entre regimes institucionais com base em princípios da justiça, em especial o princípio da diferença. Na segunda parte, composta de duas seções, encontra-se, inicialmente, uma exposição sintética da democracia econômica de Schweickart e, após, uma análise desse tipo de regime à luz do princípio da diferença.

\section{A JUSTIÇA DE RAWLS (EM ESPECIAL, O PRINCÍPIO DA DIFERENÇA) E OS REGIMES INSTITUCIONAIS.}

Para Rawls, o objeto primeiro da justiça é a estrutura básica da sociedade, que ele define como "o modo como as principais instituições sociais distribuem direitos e deveres fundamentais e determinam a divisão das vantagens da cooperação social” (Rawls, 1999, p. 6). ${ }^{1}$ A justiça, assim entendida, constitui uma base de avaliação das instituições que compõem a referida estrutura básica.

Essa atenção às instituições explica a preocupação, manifestada pelo próprio Rawls e na literatura a seu respeito, com a questão do tipo de regime institucional mais consentâneo com a justiça. ${ }^{2}$ Um tipo de regime institucional é uma representação de um certo conjunto de instituições. Em Justiça como Equidade: uma Reformulação, Rawls enumera cinco desses tipos: o capitalismo de laissez-faire, o capitalismo (ou estado) de bem-estar, o socialismo de

\footnotetext{
${ }^{1}$ No original: "the way in which the major social institutions distribute fundamental rights and duties and determine the division of advantages from social cooperation."

${ }^{2}$ RAWLS discorre sobre tipos de regime institucional e, mais particularmente, sobre um de seus tipos de regime preferidos, a democracia de cidadãos proprietários (property-owning democracy), no parágrafo 43 de "Uma Teoria da Justiça" (RAWLS, 1999) e, de maneira um pouco mais detida, na parte IV de Justiça como Equidade: uma Reformulação (RAWLS, 2001).
} 
estado, a democracia de cidadãos proprietários (property-owning democracy) e o socialismo liberal (Rawls, 2001, p. 136). Segundo Rawls, somente os dois últimos se mostram compatíveis com os princípios da justiça como equidade (Rawls, 2001, p. 138).

A questão de saber se as instituições de fato existentes (cujas características podem corresponder, de maneira mais ou menos aproximada, às de um determinado tipo de regime) atendem a princípios de justiça é uma questão cuja natureza depende, por óbvio, do conteúdo desses princípios. Quero me deter aqui sobre o princípio da diferença, mas, para contrastar, tomemos, primeiramente, o caso do princípio das liberdades básicas que, salvo no que respeita às liberdades políticas, é indiferente ao valor que a liberdade tem para cada um (Rawls, 1996, pp. 325-326). Para verificar se um regime institucional atende a esse princípio, é suficiente, portanto, atentar para o conteúdo das leis e para o modo como elas vêm sendo aplicadas pelas

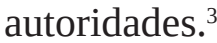

Considere, em contrapartida, o princípio da diferença (Rawls, 1999, pp. 65-73). Na versão que terei em vista inicialmente, esse princípio requer a maximização das expectativas dos cidadãos hipossuficientes no que se refere a um certo índice de bens primários que inclui a renda e a riqueza (para simplificar, tratarei o princípio da diferença por ora como princípio restrito a esses bens). ${ }^{4}$

Pois bem, a questão que se põe, então, é saber se um determinado regime institucional maximiza as expectativas dos cidadãos hipossuficientes quanto à riqueza e à renda. Essa é uma questão cuja resposta não depende, como é fácil perceber, apenas do conteúdo das leis ou da maneira como elas são aplicadas. Para o princípio da diferença, não importa como as instituições são delineadas, mas, tão somente, as consequências dessas instituições para as expectativas dos cidadãos hipossuficientes no que se refere à riqueza e à renda. O corolário

\footnotetext{
${ }^{3}$ Que o princípio das liberdades básicas se contente com a mera garantia legal dessas liberdades não significa que, para atendê-lo, seja suficiente proclamar as liberdades em questão (por exemplo, na constituição). Um Estado no qual as liberdades básicas são legalmente proclamadas, mas violadas pelas autoridades de maneira contumaz, não é justo. Apesar disso, pode-se dizer que o atendimento ao princípio das liberdades (exceção feita ao que concerne às liberdades políticas) pode ser verificado tão-somente com base na legislação e na atuação das autoridades encarregadas de aplicá-la, o que não ocorre com outros princípios da justiça como equidade, como o da diferença.

${ }^{4}$ Para discussões sobre diferentes interpretações do princípio da diferença, ver Parijs (2003) e Williams (2011). Como o princípio da diferença se subordina ao primeiro princípio e à primeira parte do segundo princípio da justiça (RAWLS, 1999, pp. 53-54 e 77), a maximização das expectativas dos cidadãos hipossuficientes quanto à riqueza e à renda deve ocorrer sob condições que não violem as liberdades básicas e a equitativa igualdade de oportunidades. Além disso, o requerimento de maximização não é impedimento à tributação (inclusive da riqueza e da renda dos mais pobres) para a provisão de bens públicos em uma medida a ser determinada democraticamente (RAWLS, 1999, pp. 249-251). Pode-se entender, portanto, que uma estrutura básica perfeitamente justa maximiza a riqueza e a renda dos cidadãos em desvantagem depois de garantidas as liberdades básicas e a equitativa igualdade de oportunidades e antes do pagamento de taxas para a provisão de bens públicos. Queralt (2013, pp. 133-134) desconsidera esse último ponto ao rejeitar a versão maximizadora do princípio da diferença.
} 
disso é que dois regimes institucionais idênticos podem ser avaliados distintamente à luz do princípio da diferença caso suas consequências sejam também distintas. ${ }^{5}$

A natureza consequencialista do princípio da diferença levanta certa suspeita sobre um debate que se proponha a aferir o tipo de regime institucional mais conforme à justiça. Não se trata, como visto, apenas do fato de que dois regimes institucionais podem apresentar diferenças entre si a despeito de pertencerem ao mesmo tipo, mas sim de que, mesmo para regimes idênticos, as consequências podem ser distintas. A afirmação de que um tipo de regime é mais consentâneo com a justiça deve ser entendida, portanto, como afirmação acerca tão somente da propensão do tipo de regime em questão a surtir certos efeitos. ${ }^{6}$

Essas observações valem para o princípio da diferença e para outras partes da concepção de justiça de Rawls cuja realização dependa das consequências das instituições que compõem a estrutura básica, tal como é o caso dos princípios do valor equitativo das liberdades políticas e da equitativa igualdade de oportunidades. O princípio da diferença, contudo (tal como o venho entendendo aqui), tem a peculiaridade de requerer a maximização das expectativas dos cidadãos hipossuficientes e, como tal, não se contentar com um certo resultado em termos absolutos. Quaisquer que sejam os efeitos de um dado regime institucional sobre as expectativas dos cidadãos hipossuficientes quanto à riqueza e à renda, somente se poderá dizer que o regime em questão se conforma ao princípio da diferença caso não haja um regime alternativo cujas consequências para as mesmas expectativas sejam ainda mais favoráveis.

Uma questão que o princípio da diferença suscita é a de saber, então, qual dos regimes a considerar para fins de comparação. Para concluir que um regime atende ao princípio da diferença, é preciso, em outras palavras, definir primeiro o conjunto de regimes relevantes para a comparação. O regime que satisfaz ao princípio da diferença será aquele que, dentre os

\footnotetext{
${ }^{5}$ Está implícito no texto acima que as expectativas dos cidadãos hipossuficientes quanto à riqueza e à renda são uma função não apenas da lei ou do modo como ela é aplicada pelas autoridades, mas também das motivações de outros cidadãos. Isso é verdadeiro tanto para uma condição de obediência parcial à legislação como para uma condição ideal de obediência total. Por exemplo, a consequência para os cidadãos hipossuficientes de uma tributação progressiva da renda depende, entre outros fatores, da motivação de certos cidadãos (os mais ricos) a seguir produzindo a despeito da tributação.

${ }^{6}$ As observações acima se coadunam com a cautela de Rawls quanto a tomar partido entre os tipos de regime da democracia proprietária e do socialismo liberal. Quando se trata de decidir entre esses dois tipos de regime, Rawls recomenda atentar "para as circunstâncias históricas da sociedade, para as suas tradições de pensamento e prática política, e muito mais" ["to society's historical circumstances, to its traditions of political thought and practice, and much else"] (RAWLS, 2001, p. 139). É possível, no entanto, que a hesitação tenha a ver não com a incapacidade de prever as consequências de cada tipo de regime, mas com as dificuldades de ordem política (maiores em alguns lugares, menores em outros) para fazê-los vingar. Em contrapartida, soa contraditória com o consequencialismo de certos princípios da justiça como equidade a rejeição peremptória de Rawls ao capitalismo de laissez-faire e ao estado de bem-estar (no caso do socialismo de estado, a alegada incompatibilidade com a justiça se deve à violação das liberdades básicas) (RAWLS, 2001, pp. 137-138).
} 
pertencentes a esse conjunto, oferecer as mais elevadas expectativas de riqueza e renda (pondose de lado, por ora, outros bens primários) para os cidadãos hipossuficientes. Apesar da sua evidente importância, esse problema da base de comparação é, de um modo geral, negligenciado por Rawls e pelo restante da literatura. Fazem parte desse conjunto apenas regimes existentes? Provavelmente não, porque, em sendo assim, o princípio da diferença perderia boa parte da sua força como ideal, já que seríamos forçados a (uma vez atendidos os demais requisitos) reconhecer algum dos regimes atuais como justo (a saber, aquele sob o qual as expectativas dos cidadãos hipossuficientes fossem as mais elevadas). Mas se a comparação não deve ficar limitada aos regimes existentes, quais, dentre os não existentes, devem ser considerados?

É de notar que todo comedimento no que toca a determinar o conjunto dos regimes relevantes para a comparação vem acompanhado por uma redução em igual medida do impulso reformista da justiça. Por exemplo, suponha que, ao descrever os regimes que compõem a base da comparação, não se atribua a nenhum deles o efeito de disseminar o ethos igualitário de Cohen (2008), isto é, o efeito de motivar os cidadãos talentosos a, apesar de não estarem legalmente constrangidos a fazê-lo, exercerem ocupações que elevem as expectativas dos cidadãos hipossuficientes. Se nenhum dos regimes considerados para comparação tem esse efeito, será forçoso concluir que um dado regime é justo à luz do princípio da diferença, porque, entre os comparados, é o que maximiza as expectativas dos cidadãos em desvantagem. Mas se um tal regime for tido como justo, então a busca por um regime que constitua um antídoto ao egoísmo deixará de ser uma questão de justiça.

Por outro lado, quanto maior a ousadia em relação aos regimes a servir de comparação, mais difícil será para regimes atuais ou vindouros atender à demanda do princípio da diferença. Retornando ao exemplo, se atribuirmos a algum dos regimes válidos para a comparação o condão de motivar os cidadãos talentosos de tal maneira que eles produzam da maneira socialmente mais útil possível sem qualquer incentivo para tanto, qualquer regime existente que fracasse em surtir esse efeito e, em consequência, torne mais acanhadas as expectativas dos cidadãos hipossuficientes, quanto à riqueza e à renda, terá de ser classificado como injusto.

Mesmo, no entanto, que o teste do princípio da diferença se mostre exigente o suficiente para que sejam considerados injustos não apenas todos os regimes institucionais atualmente existentes, mas também aqueles que, com moderado otimismo, calculemos serem capazes de sobrevir em um futuro próximo, esse princípio, ou uma versão ligeiramente modificada dele, pode ser empregado para a comparação de regimes imperfeitos (isto é, injustos 
segundo a versão do princípio que tive em vista até agora). Pode-se, em outras palavras, estipular que, todo o restante sendo igual, um regime $\mathrm{X}$ é superior a um regime $\mathrm{Y}$ se as expectativas dos cidadãos hipossuficientes quanto à riqueza e à renda são mais elevadas sob o primeiro do que sob o segundo, mesmo que nenhum desses regimes seja justo no sentido de maximizar as referidas expectativas. Daqui para a frente, tratarei o princípio da diferença como princípio apto a comparações assim.

No que se refere à comparação recém-mencionada, são de especial interesse as comparações entre regimes existentes e não existentes. Propostas de reforma institucional podem ser geralmente descritas como propostas para suplantar um regime existente por outro (ainda) não existente. ${ }^{7}$ A fim de avaliar tais propostas com base no princípio da diferença, é preciso, então, verificar sob qual regime, o existente ou o que se cogita adotar, as expectativas dos cidadãos em desvantagem serão mais elevadas. Aqui há uma questão importante a esse respeito envolvendo as consequências. É que, enquanto as consequências de um regime existente podem ser observadas ${ }^{8}$, o mesmo não se pode dizer de um regime ainda não em vigor. As consequências de regimes vindouros podem, por certo, ser estimadas, mas é de se indagar, então, segundo quais modelos comportamentais tal estimativa deve ocorrer. Será lícito presumir que um novo regime institucional altere o agir humano de maneira substancial o suficiente para fazer com que os padrões comportamentais capazes de explicar as consequências das instituições atuais tenham de ser suplantados? Sem querer subscrever a tese de uma "natureza humana” imutável, o mínimo que se pode dizer sobre isso é que as mesmas motivações e padrões de tomada de decisão verificados nas circunstâncias atuais devem ser presumidos ao se estimarem as consequências de uma nova ordem institucional, salvo se houver razão para concluir que uma reforma das instituições trará consigo alguma alteração a tal respeito. ${ }^{9}$

A comparação entre regimes institucionais (inclusive entre regimes existentes e não

\footnotetext{
${ }^{7}$ Mesmo quando a proposta de reforma almeja replicar instituições existentes em outro lugar (ou no mesmo lugar, mas em outra época), justifica-se tratar o regime proposto como não existente não apenas porque de fato ele não existe no lugar para o qual está sendo proposto, mas também porque compartilha características de regimes inéditos. Como, ao menos no que concerne a princípios de justiça como o da diferença, o que importa são as consequências de um regime institucional, e como um mesmo arranjo institucional pode ter consequências distintas em épocas e lugares distintos, um regime novo, mesmo quando replique características de regimes existentes em outra época ou lugar, tem consequências incertas em alguma medida (conquanto possivelmente não na mesma medida de regimes inéditos).

${ }^{8} \mathrm{O}$ que não é o mesmo que dizer que podem ser facilmente observadas. As consequências de regimes existentes são, em todo caso, tema apto à investigação empírica.

${ }^{9}$ Uma questão lateral consiste em saber como avaliar uma proposta de reforma institucional cujas consequências previstas somente favoreçam as expectativas dos cidadãos hipossuficientes a longo prazo. Que taxa de desconto deve ser aplicada aos benefícios mediatos de um novo regime?
} 
existentes) torna-se mais complicada quando se incluem outros bens, além da riqueza e da renda, entre aqueles cuja distribuição se sujeita ao princípio da diferença. Há, quanto a isso, duas possibilidades. Uma consiste em aplicar o princípio da diferença à distribuição de outros dos bens primários mencionados por Rawls, como os "poderes, prerrogativas e posições de responsabilidade” e as "bases sociais do autorrespeito” (FREEMAN, 2007, p. 113; ARNOLD, 2012; O’NEILL, 2012). A segunda possibilidade decorre do fato de se considerar a lista de bens primários como “aberta”, isto é, não exaustiva. Rawls está claramente em concordância com isso, tal como se depreende, por exemplo, da seguinte passagem:

Podemos, caso necessário, incluir no índice [de bens primários] dotações inatas cultivadas e até estados de consciência, como a dor física. A fim, no entanto, de tratar com o que é objetivamente mensurável e depender apenas de informações prontamente disponíveis e fáceis de entender, é bem melhor que tais bens não sejam incluídos. O tempo para lazer, em contrapartida, pode ser medido objetivamente e aos olhos de todos. Ele também atende à essencial condição de que os bens primários não pressuponham alguma doutrina compreensiva (RAWLS, 2001, p. 179). ${ }^{10}$

No trecho acima, Rawls não deixa dúvida de que considera o rol de bens primários encontrado em outras partes de seus trabalhos (por exemplo, em RAWLS, 1996, p. 181) como não exaustivo. Ele também esboça as condições para que algo seja tratado como bem primário, a saber: a) que o estado da distribuição do bem em questão seja objetivamente verificável; e b) que esse bem não pressuponha um certa doutrina compreensiva, isto é, não tenha particular relação com determinada concepção da boa vida. ${ }^{11}$ Tendo isso em vista, podem ser tidos como bens primários sujeitos ao princípio da diferença, além do lazer, o trabalho (em geral), o trabalho significativo (desde que se defina "significativo" de tal maneira que as características do trabalho significativo sejam objetivamente verificáveis $)^{12}$ e o poder de gestão da empresa. ${ }^{13}$

Devido à diversidade dos bens primários subordinados ao princípio da diferença, surge o problema da comparação, à luz desse princípio, entre regimes institucionais cujo sucesso ao

\footnotetext{
${ }^{10}$ No original: "If necessary we can also include in the index realized native endowments and even states of consciousness like physical pain. However, for the sake of having an objective measure and relying on information that is readily available and easy to comprehend, it is much better not to include such goods in the index. But leisure time has a reasonably objective measure and is open to view. It also meets the essential condition that primary goods must not presuppose any particular comprehensive doctrine."

${ }^{11}$ Mais sobre a "flexibilidade” do rol de bens primários encontra-se em Rawls (2001, pp.168- 176; 1996, pp. 178187).

${ }^{12}$ Para a ideia de que a oportunidade para o trabalho significativo pode ser uma das bases sociais do autorrespeito, ver Moriarty (2009). Arnold (2012), por sua vez, afirma que uma distribuição mais equânime do trabalho significativo ou "complexo" constitui uma decorrência da inclusão do bem primário dos poderes, prerrogativas e posições de responsabilidade entre os bens regulados pelo princípio da diferença. Repare-se, entretanto, que, uma vez definido, como faz Arneson (1987, p. 517), em termos objetivos (como o trabalho "interessante, que requer inteligência e iniciativa” [“interesting, calling for intelligence and initiative”]), o trabalho significativo pode ser tratado como bem primário em si mesmo.

${ }^{13}$ Argumentos que apelam para o princípio da diferença em favor de uma distribuição mais igualitária do poder de gestão da empresa relacionam a democracia no local de trabalho a bens primários como poderes, prerrogativas e posições de responsabilidade e bases sociais do autorrespeito. Ver, a respeito, O’Neill (2008) e Arnold (2012).
} 
elevar as expectativas dos cidadãos hipossuficientes quanto aos bens em questão varie. Isso é pouco provável quando os bens primários considerados são apenas a riqueza e a renda. Dificilmente um regime $\mathrm{X}$, cuja consequências para a renda dos cidadãos em desvantagem sejam superiores às de um regime $\mathrm{Y}$, deixará de ter vantagem sobre esse último também em relação à riqueza. O mesmo não se pode dizer, todavia, quanto a outros bens. Não é implausível que o regime $\mathrm{Y}$ cause menos desemprego do que o regime $\mathrm{X}$ e se saia, portanto, melhor no que toca a elevar expectativas quanto aos bens primários do emprego e do trabalho significativo, mas que, em contrapartida, a riqueza e a renda dos cidadãos hipossuficientes (graças, por exemplo, a um generoso seguro-desemprego) sejam mais altas em $\mathrm{X}$ do que em $\mathrm{Y}$.

Como tratar o problema da comparação entre regimes com consequências contraditórias em relação aos diferentes bens primários sujeitos ao princípio da diferença? ${ }^{14}$ Quanto a isso, é de notar, em primeiro lugar, que o fato de os bens em questão serem incomensuráveis não significa que dois regimes com efeitos diversos sobre as expectativas dos cidadãos em desvantagem no tocante a esses bens sejam incomparáveis. ${ }^{15}$ Dois bens são incomensuráveis, no sentido que se tem em vista aqui, se não há uma medida de equivalência entre eles (por exemplo, se não é possível definir quantos \$n em renda correspondem a uma redução $n \%$ do desemprego ou a uma melhora $n$ no índice relativo à distribuição do trabalho significativo). Para concluir que a falta dessa medida de equivalência implica a incomparabilidade (à luz do princípio da diferença) de regimes, seria preciso concordar com a afirmação de que um regime que eleva as expectativas dos cidadãos hipossuficientes quanto ao trabalho e as piora quanto à renda sob hipótese alguma é melhor, pior ou igual a um regime cujos efeitos são inversos. Essa, porém, é uma afirmação pouco plausível. Se o regime X oferece aos cidadãos em desvantagem perspectivas muito melhores do que as de Y quanto ao emprego e uma (expectativa de) renda apenas ligeiramente inferior, é difícil resistir à conclusão de que $\mathrm{X}$ é melhor do que $\mathrm{Y}$ e de que os dois regimes são, portanto, comparáveis.

Naturalmente, uma coisa é dizer que alguns regimes com consequências heterogêneas em relação aos bens primários sujeitos ao princípio da diferença são comparáveis, e outra é dizer que regimes com essas características são sempre comparáveis. Tendo em vista não ser possível tratar aqui da controvérsia filosófica a respeito, ${ }^{16}$ limitar-me-ei a supor que, ao menos em alguns casos, não seja possível afirmar, de dois regimes institucionais X e Y, nem que um é melhor do que o outro, nem que os dois são iguais (e que, portanto, os regimes em questão são incomparáveis). A implicação disso é que se dois regimes são incomparáveis segundo o

\footnotetext{
${ }^{14}$ O problema aludido acima é, em outras palavras, o de comparar regimes entre os quais não haja uma relação de dominância de Pareto. No que respeita ao princípio da diferença, um regime domina paretianamente o outro se sob ele as expectativas dos cidadãos hipossuficientes são mais elevadas quanto a pelo menos um dos bens primários sujeitos ao princípio da diferença e não menores quanto a todos os demais.

15 Sobre a distinção entre incomensurabilidade e incomparabilidade, ver Chang (1997, p. 1-2).

${ }^{16}$ Sobre isso, podem-se consultar os trabalhos reunidos em Chang (1997) e Chang (2002). A própria Chang, uma defensora do alargamento da noção de comparabilidade, não deixa de reconhecer instâncias em que portadores de valores diversos são incomparáveis.
} 
princípio da diferença (e iguais, ou também incomparáveis, em relação aos demais princípios da justiça), então a eleição entre esses regimes deixa de ser uma questão de justiça.

\section{A DEMOCRACIA ECONÔMICA DE SCHWEICKART E O PRINCÍPIO DA DIFERENÇA.}

A segunda parte do artigo será dedicada à democracia econômica, tipo de regime institucional defendido por Schweickart (2011; 2012). Schweickart (2012) afirma que a democracia econômica é mais propensa a atender às demandas da justiça de Rawls, mais até mesmo do que a democracia de proprietários. A primeira parte desta seção resume as características da democracia econômica, enquanto que a segunda se vale das considerações precedentes para avaliar a conformidade desse tipo de regime ao princípio da diferença.

\subsection{A DEMOCRACIA ECONÔMICA: APRESENTAÇÃO SINTÉTICA.}

Cinco características resumem a democracia econômica (doravante, DE): a) propriedade pública dos meios de produção; b) gestão democrática da empresa (segundo a regra "uma pessoa, um voto”); c) investimento público; d) produção orientada pelo mercado; e) mercado de trabalho.

a) Propriedade pública dos meios de produção

Na DE, a propriedade privada dos meios de produção somente é admitida para empresas de pequeno porte. Nas grandes empresas, os bens de produção pertencem ao Estado, e os trabalhadores, que os controlam, devem reservar parte dos ganhos da empresa para o pagamento de um tributo pelo uso desses bens e para fazer frente à sua depreciação (SCHWEICKART, 2011, posições 1.479-1.486).

b) Gestão democrática da empresa (segundo a regra “uma pessoa, um voto”)

As empresas na DE (exceção feita, uma vez mais, às empresas de pequeno porte) são geridas pelos trabalhadores de acordo com a regra "uma pessoa, um voto". Diretores e administradores são designados pelos trabalhadores direta ou indiretamente, por um conselho de administração com representantes eleitos (SCHWEICKART, 2011, posições 1.464-1.473).

c) Investimento público

Nas (grandes) empresas da DE, o investimento é ou autofinanciado (isto é, financiado pelos ganhos da própria empresa, que os trabalhadores podem decidir investir ao invés de repartir entre si) ou financiado mediante empréstimos públicos. Não há bancos privados, nem é admitido o financiamento pela emissão de ações a serem adquiridas por investidores privados. 
Empréstimos públicos são feitos às empresas diretamente pelo Estado ou por bancos públicos, e a quantidade de fundos disponíveis para as empresas de cada região é, em princípio, proporcional à população (SCHWEICKART, 2011, posições 1.524-1.528).

\section{d) Produção orientada para o mercado}

Em contraste com as experiências socialistas de planejamento central, a DE é um tipo de regime de socialismo de mercado, em que a decisão sobre o que e quanto produzir é tomada no âmbito de cada empresa (SCHWEICKART, 2011, posições 1.464-1.465). As empresas são incentivadas a obter lucro até o ponto em que a renda (ou os “dividendos”) dos trabalhadores são maximizados e, para tanto, devem procurar atender às preferências dos consumidores (SCHWEICKART, 2011, posições 1.505-1.511).

\section{e) Mercado de trabalho}

Empresas e trabalhadores são livres quanto à contratação e ao ajuste das condições de trabalho. Isso significa que um trabalhador pode decidir abandonar uma empresa por outra e que empresas podem decidir dispensar trabalhadores, sempre obedecendo à regra de gestão democrática. Além disso, as empresas podem oferecer maior salário ou condições mais vantajosas a fim de atrair ou manter trabalhadores com certas aptidões (SCHWEICKART, 2011, posições 1.466-1.468).

\subsection{DEMOCRACIA ECONÔMICA E JUSTIÇAA RAWLSIANA.}

Quais são as razões para acreditar que a DE seja superior ao capitalismo no que respeita ao princípio da diferença? Convém esclarecer, primeiro, que limitar a atenção a esse princípio se justifica aqui tendo em vista que a DE satisfaz ao princípio das liberdades básicas no que se refere à garantia legal dessas liberdades (SCHWEICKART, 2011, posição 3.940). Além disso, parece aceitável postular que a DE tenha, em geral, um efeito sobre as desigualdades de riqueza e renda que a torne no mínimo tão eficaz quanto os tipos de regime capitalistas em relação ao valor equitativo das liberdades políticas e à equitativa igualdade de oportunidades. ${ }^{17}$ Logo, se ficar demonstrado que a DE é superior ao capitalismo no que se refere ao princípio da

\footnotetext{
${ }^{17}$ De um ponto de vista estritamente rawlsiano, bastaria que a DE se mostrasse ligeiramente superior quanto ao valor equitativo das liberdades políticas ou à equitativa igualdade de oportunidades para sobrepujar os regimes existentes em termos de justiça, tendo em vista a prioridade léxica do primeiro sobre o segundo princípio da justiça e da equitativa igualdade de oportunidades sobre o princípio da diferença (RAWLS, 1999, pp. 53-54 e 77). Penso, porém, que a comparação baseada no princípio da diferença ainda assim se justifica, ou porque a DE pode não apresentar uma vantagem nítida sobre os tipos de regime capitalistas em relação aos demais princípios da justiça como equidade, ou porque as estritas relações de prioridade entre os princípios da justiça de Rawls, em particular entre a equitativa igualdade de oportunidades e o princípio da diferença, podem não ser defensáveis. Sobre esse último ponto, ver Arneson (1999).
} 
diferença, é bem possível que Schweickart esteja certo ao afirmar que rawlsianos devem endossar o socialismo (ao menos, o socialismo da DE).

Antes de prosseguir com a análise da DE à luz do princípio da diferença, convém recordar algumas das considerações metodológicas da parte anterior. Primeiro, tendo em vista a natureza consequencialista do princípio em questão, é preciso ter cuidado ao comparar tipos de regime institucional, pois o que importa não é propriamente o arranjo institucional corresponde a cada tipo, mas as consequências de manifestações reais do tipo em questão. A análise baseada em tipos somente se justifica à medida que um determinado tipo de regime se mostre propenso a surtir certos efeitos independentemente de circunstâncias de tempo e lugar. Segundo, há a questão da comparação entre regimes existentes e não existentes e do modo de estimar as consequências desses últimos. Tal como dito acima, à falta de uma razão para tanto, não se devem atribuir a regimes não existentes consequências motivacionais distintas das observadas sob os atuais regimes. Schweickart se mostra bastante sóbrio a esse respeito, manifestando a expectativa de que a DE seja capaz de dar lugar a um mundo melhor mediante mudanças eminentemente institucionais. ${ }^{18}$

Tendo em vista a descrição feita por Schweickart, os principais argumentos em favor da DE em relação a regimes capitalistas estão relacionados ao trabalho. Para entender esses argumentos, é preciso considerar, primeiro, certa implicação do investimento privado para os regimes capitalistas. A fim de atrair investidores, toda empresa capitalista lucrativa tem um incentivo para se expandir, já que, todo o restante sendo igual, quanto maior o volume de atividade, maiores os lucros e, em consequência, mais atrativa se torna a empresa para os que nela investem. Esse mesmo incentivo à expansão não existe nas empresas da DE, já que, para essas últimas, o aumento da produção só se mostra vantajoso à medida que haja ganhos de escala (SCHWEICKART, 2011, posições 2.275-2.276). ${ }^{19}$ Caso contrário, a ampliação da atividade terá de vir acompanhada de um aumento (no mínimo) proporcional do número de trabalhadores, sem benefício para a renda de cada trabalhador individualmente considerado. ${ }^{20}$

\footnotetext{
18 Schweickart (2011, posição 2.238): “A democracia econômica não oferece abrigo para a Utopia, mas, se fizermos algumas pequenas mudanças estruturais, um mundo bem melhor do que a maioria de nós imagina se tornará possível." ("Economic democracy will not usher in Utopia, but if we make a few structural changes, a far better world becomes possible than most of us can now imagine").

${ }^{19}$ Outro fator que reduz o estímulo à expansão é o interesse dos trabalhadores em conservar o poder sobre a gestão, que se dilui à medida que o número de trabalhadores empregados em uma empresa aumenta (SCHWEICKART, 2011, posições 2.278-2.285).

${ }^{20}$ Mas o que impede que os trabalhadores mais antigos se apropriem de parte dos lucros decorrentes do aumento da produção mediante o pagamento de salários menores aos recém contratados? Isso é, em tese, possível, já que, como dito, diferenças salariais são admitidas na DE. O ponto é importante porque, como se verá adiante no texto, boa parte das vantagens que podem ser atribuídas à DE no que toca ao princípio da diferença estão relacionadas
} 
Pois bem, que consequências advêm do fato de o incentivo à expansão da atividade ser menor nas empresas da DE? Observe que, a exemplo das empresas capitalistas, a ineficiência é um problema para as empresas da DE. Como a produção na DE é orientada pelo mercado, empresas ineficientes sujeitam-se a ser sobrepujadas por outras. A diferença é que, na DE, esse risco é menor. Uma empresa ineficiente corre o risco de ser superada por novas empresas, mas não pelas empresas já existentes que já tenham atingido o seu limite de expansão. ${ }^{21}$ Em regimes capitalistas, em contrapartida, as empresas são, em geral, estimuladas a tomar para si a fatia de mercado de uma concorrente ineficiente.

Aliada à gestão democrática, a particularidade recém referida propicia condições de trabalho mais benéficas para as empresas da DE ainda quando essas condições sacrifiquem (em alguma medida) a eficiência. Isso tem implicações para a permanência no emprego, para a duração da jornada (e, portanto, para o tempo disponível para lazer) e para a divisão do trabalho significativo, bens primários cuja distribuição se sujeita ao princípio da diferença. Examinarei cada um dos casos separadamente.

Deve-se esperar que haja mais relutância em dispensar trabalhadores nas empresas da DE? Uma razão para pensar que sim é, como afirmado, o fato de uma eventual ineficiência provocada por essa relutância não oferecer tanto risco para as empresas da DE quanto para as suas congêneres capitalistas. Outra razão é o controle da gestão pelos trabalhadores. Administradores que se mostrem implacáveis nas dispensas de trabalhadores (sobretudo quando essas dispensas forem injustificadas) têm pouca chance de manter o apoio do conselho de administração das empresas geridas democraticamente. Isso pode ser visto como consequência do autointeresse puro e simples, já que uma administração que não mostra hesitação ao fazer cortes constitui uma ameaça para os trabalhadores. Com um pouco mais de cautela, pode-se ainda aventar que um certo esprit de corps entre os trabalhadores contribua para a estabilidade no emprego.22

ao incentivo à expansão da empresa. O que é permitido dizer em relação à contratação de novos trabalhadores nas empresas da DE é que se, por um lado, essa contratação pode ocorrer sob condições que levem os trabalhadores mais antigos a se locupletarem à custa dos mais novos, por outro, a gestão democrática da empresa deve ao menos impor certos limites a essa exploração. Em todo o caso, a possibilidade de diferenciação salarial constitui uma ressalva à ideia (ver, sobre isso, a nota anterior) de que o crescimento das empresas na DE é limitado ao ponto em que o ganho marginal de escala se torna iguais a zero.

${ }^{21}$ Em condições de concorrência perfeita, sempre haverá novas empresas para suplantar uma empresa ineficiente. É sabido, entretanto, que essas condições nem sempre se verificam.

22 Schweickart (2011, posição 2.255) refere-se à “natural solidariedade engendrada pela democracia” ("the natural solidarity engendered by democracy”). Certa cautela se justifica, não obstante, porque, diferentemente do que ocorre nas empresas capitalistas, a solidariedade entre os trabalhadores nas empresas da DE é potencialmente contrária ao interesse de cada trabalhador na maximização dos seus dividendos. Na literatura econômica sobre as cooperativas, é interessante notar que, contra a previsão standard sobre o objetivo da maximização da renda per 
Schweickart (2011, posições 2.569-2.646) apresenta um outro argumento em favor da DE no que se refere ao emprego. Segundo ele, no capitalismo, o desemprego é não apenas uma consequência cíclica, como também um meio indispensável de disciplinar a força de trabalho. Em outras palavras, a ameaça de desemprego é necessária para assegurar um bom desempenho de trabalhadores assalariados indiferentes ao sucesso da empresa. Na DE, em contraste, se, por um lado, não há nada capaz de assegurar, por si só, o pleno emprego, por outro, o fato de o desemprego não ter a mesma importância estratégica dos regimes capitalistas é propício a que o Estado atue mais eficazmente para eliminá-lo, seja orientando o investimento público à criação de postos de trabalho, seja como “empregador de último recurso" (employer of last resort).

Passemos ao caso do lazer (SCHWEICKART, 2011, posições 2.473-2.780). Tal como ocorre com a estabilidade no emprego, a DE possui características que favorecem a redução da jornada de trabalho e, em consequência, o aumento do tempo disponível para o lazer. Em primeiro lugar, como observado acima, a DE abranda o risco advindo de decisões contrárias à eficiência. Frequentemente, a decisão em favor do encurtamento da jornada de trabalho é uma decisão dessa natureza, já que eleva o número de trabalhadores necessário para produzir a mesma quantidade e impõe custos adicionais com treinamento. ${ }^{23}$ Além disso, o controle democrático da gestão favorece uma decisão quanto à duração da jornada que atenda ao interesse dos trabalhadores pelo aumento do tempo livre (ou que faculte a cada um determinar a duração da sua jornada), ainda que com algum sacrifício da eficiência. ${ }^{24}$

Considerações similares se aplicam, por fim, ao trabalho significativo (SCHWEICKART, 2011, posição 2.771). À medida que uma divisão mais equânime das tarefas interessantes seja uma causa de ineficiência (porque eleva custos com treinamento, ou faz com que se abra mão dos ganhos de produtividade decorrentes da especialização), as empresas da DE estão, como dito, mais aptas a suportá-la. Admitindo-se que haja por parte dos trabalhadores em geral um interesse em evitar tarefas maçantes, pode-se esperar que a gestão

capita (WARD, 1958), há evidências de que as cooperativas sacrificam em alguma medida esse objetivo em prol da preservação do emprego. A esse respeito, ver, por exemplo, Craig e Pencavel (1993).

${ }^{23}$ Há, na verdade, duas causas possíveis de ineficiência relacionadas à duração da jornada de trabalho. Do ponto de vista da eficiência, a jornada pode ser curta demais se, em média, cada trabalhador poderia trabalhar por mais tempo sem perda de produtividade, ou sem uma perda de produtividade significativa o suficiente para compensar os custos com a contratação de um número maior de trabalhadores. Por outro lado, a jornada também pode ser longa demais se o aumento do número de horas trabalhadas acarretar uma perda significativa de produtividade. Em empresas nas quais cada trabalhador tenha a liberdade para determinar a duração da própria jornada, as duas causas de ineficiência podem se fazer presentes.

${ }^{24} \mathrm{O}$ fato de a DE fazer com que decisões pela redução da jornada de trabalho se tornem mais comuns também pode colaborar para a redução do desemprego (SCHWEICKART, 2011, posições 2.783-2.786). 
democrática da empresa contribua para que essas tarefas sejam mais equanimemente repartidas do que nas empresas capitalistas.

Pode-se afirmar, pois, que a DE possui características propícias a oferecer a todos (e, em particular, aos cidadãos em desvantagem devido a contingências sociais ou à distribuição desigual de aptidões inatas) mais estabilidade no emprego, mais tempo disponível para o lazer e distribuição mais equânime do trabalho significativo, todos eles considerados bens primários (ou meios para bens primários, como as bases sociais do autorrespeito) abarcados pelo princípio da diferença de Rawls. Além disso, caso a democracia no trabalho seja também um desses bens primários (ou meio para a realização de um), a DE tem uma vantagem óbvia sobre os regimes capitalistas.

Em contrapartida, é impossível determinar de antemão a medida da superioridade da DE com relação aos bens primários em questão. Como foi possível notar, parte substancial da vantagem atribuída à DE quanto ao emprego, ao lazer e ao trabalho significativo se baseia na suposição de que a ineficiência se mostra mais tolerável sob esse tipo de regime, devido à falta de incentivo para a expansão da empresa (ou para a expansão além do ponto em que deixa de haver ganhos de escala). Como estão sujeitas a concorrência, as empresas da DE podem ser castigadas pela ineficiência. Decisões na gestão da empresa que favoreçam a manutenção do emprego, a redução da jornada e a melhora na distribuição do trabalho significativo à custa da eficiência sempre trarão consigo um certo risco e dependerão, em consequência, do peso atribuído aos benefícios de curto prazo que essas decisões proporcionam. ${ }^{25}$

As empresas da DE também se sujeitam a apresentar uma distribuição desigual do poder de gestão, não obstante a regra "uma pessoa, um voto”. Essa desigualdade pode ser ensejada pelas especiais aptidões de alguns trabalhadores, combinada à sujeição das relações de trabalho ao mercado. Trabalhadores cujos talentos sejam raros e necessários podem, assim, sob a ameaça de abandonar a empresa, acabar exercendo maior influência sobre a gestão. ${ }^{26}$ Isso é particularmente preocupante se tivermos em vista que são as expectativas dos outros trabalhadores, aqueles cujos atributos são menos cobiçados (e que) correm o risco de ser subjugados pelos talentosos), as que importam para o princípio da diferença. ${ }^{27}$

\footnotetext{
${ }^{25} \mathrm{O}$ que também pode dar lugar a decisões pela provisão dos bens primários em questão e contrárias à eficiência é, pois, uma certa “miopia” que leve os trabalhadores a negligenciar o interesse de longo prazo na continuidade da empresa.

${ }^{26}$ É evidente que isso também ocorre em empresas capitalistas. Acima, apenas se chama a atenção para o fato de que a propriedade dos meios de produção não é a única causa possível de hierarquização da gestão.

${ }^{27}$ Note que o fato de a redução das desigualdades de riqueza e renda favorecer a equitativa igualdade de oportunidades, um dos argumentos usados para defender a democracia proprietária (RAWLS, 2001, p. 138;
} 
Deve-se ter em vista, além disso, que a DE se inclina a reduzir as expectativas dos cidadãos hipossuficientes quanto aos bens primários da riqueza e da renda. Isso é reconhecido pelo próprio Schweickart ao mencionar a constante necessidade de crescimento da produção sob o capitalismo (e os seus indesejáveis efeitos ambientais). Há várias razões para supor que a DE traga consigo um declínio geral (e inclusive, pois, para os cidadãos em desvantagem) da riqueza e da renda, algumas das quais já foram aludidas acima. Primeiro, e como já dito, a DE reduz a concorrência entre as empresas (devido à falta de incentivo para expansão) e, ao fazêlo, dá causa a ineficiência. ${ }^{28}$ Segundo, e aliado ao primeiro, a gestão democrática enseja que certas decisões conformes aos interesses dos trabalhadores (por exemplo, o interesse pela redução da jornada) sejam tomadas com sacrifício da eficiência. Terceiro, há o problema da inovação. Se tivermos em vista o fato de que o investimento em inovação constitui um meio de expansão, então a mesma falta de incentivo à expansão que ameniza a competição acaba sendo um entrave à inovação. ${ }^{29}$

Qual é a importância do fato de a economia da DE ser previsivelmente menos vigorosa, e, em consequência, reduzir a longo prazo as expectativas de renda e riqueza, para uma análise desse tipo de regime segundo o princípio da diferença? Schweickart chama a atenção, a esse respeito, para uma passagem sobre o princípio da poupança justa na qual Rawls (1999, p. 258) afirma que “além de um certo ponto [a riqueza] se torna provavelmente um obstáculo, uma distração irrelevante na melhor das hipóteses, quando não uma tentação à indulgência e ao vazio.” ${ }^{30}$ Essa passagem, comenta Schweickart (2012, p. 257), mostra que a riqueza não é um valor para Rawls e que, portanto, o fato de a DE não induzir ao crescimento da riqueza, nos mesmos moldes de regimes capitalistas, deve ser tratado por rawlsianos como de somenos importância. No entanto, que a riqueza não seja, em si mesma, um valor para Rawls

FREEMAN, 2007, p. 227; em outro sentido, O’NEILL, 2012), não afasta o temor de que trabalhadores mais capacitados ditem as regras nas empresas da DE. A plena realização da equitativa igualdade de oportunidades não previne que haja trabalhadores cujas aptidões estejam sob maior demanda do que as de outros, mas apenas faz com que a diferente capacitação esteja mais relacionada à "loteria natural” (isto é, aos desiguais dotes inatos) do que a circunstâncias sociais. Sobre o princípio da equitativa igualdade de oportunidades como princípio que procura atrelar às chances de sucesso às aptidões inatas, ver Rawls (1999, p. 63).

${ }^{28}$ Naturalmente, a falta de concorrência e o risco de ineficiência dela decorrente também se verificam em regimes capitalistas devido à formação de oligopólios. A diferença quanto a isso é que, na DE, o controle democrático da gestão colabora para que certas decisões ineficientes sejam tomadas em favor dos trabalhadores.

${ }^{29}$ É impossível enfrentar aqui o já antigo e sofisticado debate microeconômico sobre a produção em cooperativas. Embora esse debate seja possivelmente útil para avaliar os méritos da DE na versão defendida por Schweickart, deve-se ter em vista o fato de que o comportamento das empresas na DE pode não coincidir com os de cooperativas existentes (mesmo daquelas que não se valham de trabalho assalariado) que se sujeitam à concorrência de empresas capitalistas.

30 “(B)eyond some point it [wealth] is more likely to be a positive hindrance, a meaningless distraction at best if not a temptation to indulgence and emptiness." 
é algo que não autoriza concluir pela sua irrelevância para a comparação de arranjos institucionais. A riqueza e a renda são bens primários, no sentido de Rawls, devido ao seu papel instrumental para o exercício das capacidades morais (em particular, a capacidade para uma concepção do bem). ${ }^{31}$ Não há dúvida, assim, de que, quando se comparam dois regimes institucionais à luz da justiça rawlsiana, preferível aquele sob o qual as expectativas de riqueza dos cidadãos hipossuficientes são mais altas, todo o restante sendo igual. ${ }^{32}$

Isso não significa que o princípio da diferença leve a rejeitar a DE quando comparada a regimes capitalistas, porque, se (como parece) as expectativas de riqueza e renda dos cidadãos hipossuficientes são maiores sob esses últimos, o restante, tal como visto ao longo desta seção, não é igual. Há boas razões para prever que, em regimes de DE, as expectativas dos cidadãos em desvantagem quanto a outros bens primários (poderes, prerrogativas e posições de responsabilidade, bases sociais do autorrespeito, emprego, lazer, trabalho significativo e democracia no trabalho) sejam mais elevadas. É possível, por isso, que, entre a DE e o estado de bem-estar (ou o tipo de regime capitalista preferido por Rawls, a democracia de cidadãos proprietários), o princípio da diferença, ao invés de indicar uma preferência tout court por um tipo de regime, sirva somente para comparar particulares versões de um e outro tipo, bem como conduza, em muitos casos, a um juízo de incomparabilidade.

Por fim, mesmo que, tendo em vista suas consequências de curto prazo, a DE e o capitalismo se mostrem incomparáveis (ou até comparáveis com vantagem para a primeira), uma questão a enfrentar é a da estabilidade da DE. Sobre isso, uma observação a fazer é que essa estabilidade depende das preferências dos cidadãos pelos bens primários (como lazer, democracia no trabalho e trabalho significativo) que a DE oferece em maior profusão. Essas

\footnotetext{
${ }^{31}$ Sobre a relação entre a noção de bem primário e as duas capacidades morais fundamentais, as capacidades para um senso de justiça e para uma concepção de bem, ver Rawls (2001, p. 169).

${ }^{32} \mathrm{Na}$ sua comparação entre a DE e a democracia de cidadãos proprietários, Schweickart enfrenta o problema das desigualdades de riqueza (que ele admite serem tendencialmente menores na democracia de cidadãos proprietários do que na DE, mas, em todo o caso, menores sob ambos os tipos de regime do que sob o Estado de bem-estar). Do ponto de vista do princípio da diferença, entretanto, o que importa não são as diferenças de riqueza em si mesmas, mas se essas diferenças são ou não necessárias para maximizar as expectativas dos cidadãos hipossuficientes. Assim sendo, não serve, por si só, como argumento em favor da DE (nem, tampouco, da democracia de cidadãos proprietários) o de que ela reduz as desigualdades de riqueza e renda se, em regimes capitalistas, essas desigualdades, apesar de maiores, acabarem elevando as expectativas dos cidadãos em desvantagem em relação aos bens primários em questão. Essa conclusão será inescapável à medida que limitarmos nossa atenção ao princípio da diferença entendido como princípio atinente à riqueza e à renda. Pode-se, por outro lado, argumentar em favor de um tipo de regime que reduza desigualdades com base em outros princípios da justiça que não o da diferença (por exemplo, os princípios do valor equitativo das liberdades políticas e da equitativa igualdade de oportunidades) ou até com base no princípio da diferença mesmo, caso se entenda que a redução da desigualdade ajude a elevar expectativas quanto a outros bens primários, tal como quando se alega, por exemplo, que uma desigualdade material robusta tem como efeito o de minar as bases sociais do autorrespeito (PENNY, 2013).
} 
preferências precisam ser intensas o suficiente para que uma eventual falta de crescimento ou até diminuição da riqueza e da renda não causem maior descontentamento e, com isso, acabem tornando a solução institucional uma questão instável. ${ }^{33}$

\section{CONCLUSÃO}

Neste trabalho, tratei do potencial de um tipo de regime de socialismo de mercado, a democracia econômica (DE) de Schweickart (2011; 2012), para satisfazer ao princípio da diferença de Rawls. Depois de algumas considerações metodológicas na primeira parte sobre a comparação de regimes institucionais com base em princípios da justiça (em particular, o princípio da diferença), a segunda parte apresentou os pontos principais da proposta de Schweickart e avaliou suas possíveis consequências para a distribuição de bens primários. A mais importante conclusão é que a democracia econômica não é definitivamente superior a regimes capitalistas no que se refere ao princípio da diferença, mas pode, em determinadas circunstâncias, mostrar-se superior ou incomparável com esses regimes, devido à sua tendência a elevar as expectativas dos cidadãos hipossuficientes quanto a outros bens primários que não a riqueza e a renda. Por fim, ponderou-se que a estabilidade de um regime de DE pode depender de que as suas consequências (quando comparadas às de outros regimes) não estejam em substancial desajuste com as preferências dos cidadãos. Isso equivale a dizer que o sucesso a longo prazo de um regime de DE depende da intensidade das preferências dos cidadãos por bens primários como o lazer, o trabalho significativo e a democracia no trabalho.

\section{REFERÊNCIAS}

ANALYSE \& KRITIK. 2013. Zurique: v. 35, n. 1.

ARNESON, R. J. Meaningful work and market socialism. Ethics, v. 97, n. 3, pp. 517-545, 1987. 1999.

Against Rawlsian equality of opportunity. Philosophical Studies, v. 93, pp. 77-112,

\footnotetext{
${ }^{33}$ Duas observações adicionais. Primeiro, repare que, tanto no caso da DE quanto no dos regimes capitalistas, a combinação de riqueza, renda e outros bens primários não depende exclusivamente de decisões individuais. Assim como os cidadãos de regimes capitalistas podem em geral desejar que haja mais tempo disponível para lazer (ainda que com certo sacrifício de riqueza e renda) mas, devido a circunstâncias institucionais, falhar em coordenar suas ações de modo a alcançar esse objetivo, a DE pode, por razões análogas, deixar de atender às aspirações dos trabalhadores quanto à riqueza e à renda. Segundo, não se deve confundir o que é dito acima com a afirmação de que, na comparação entre regimes que oferecem diferentes "pacotes" de bens primários com base no princípio da diferença, deva-se considerar superior o regime que mais se conforme às preferências dos cidadãos. Isso seria incorreto pela simples razão de que o princípio da diferença é um princípio de maximização das expectativas (dos cidadãos em desvantagem) quanto a bens primários, e não um princípio para a satisfação de preferências. O que se pondera acima é que, entre dois regimes cujas consequências são a curto prazo distintas e (devido à diversidade de bens primários envolvidos), incomparáveis à luz do princípio em exame, um regime cuja combinação de bens primários desatenda às preferências dos cidadãos é um regime tendencialmente mais instável.
} 
ARNOLD, S. The difference principle at work. Journal of Political Philosophy, v. 20, n. 1, pp. 94-118, 2012.

CHANG, R. Introduction. In: CHANG, R. (org). Incommensurability, incomparability, and practical reason. Cambridge: Harvard University Press, 1997, pp. 1-34, 1997.

. The possibility of parity. Ethics, v. 112, n. 4, pp. 659-688, 2002.

COHEN, G. A. Rescuing justice and equality. Cambridge: Harvard University Press, 2008.

CRAIG, B; PENCAVEL, J. The objectives of worker cooperatives. Journal of Comparative Economics, v. 17, pp. 288-308, 1993.

FREEMAN, S. R. Rawls. Nova York: Routledge, 2007.

MORIARTY, J. Rawls, self-respect, and the opportunity for meaningful work. Social Theory and Practice, v. 35, n. 3, p. 441-459, 2009.

O’NEILL, M. Three Rawlsian routes towards economic democracy. Revue de Philosophie Économique, v. 8, n. 2, pp. 29-55, 2008.

. Free (and fair) markets without capitalism: Political values, principles of justice, and property-owning democracy. In: O’NEILL; M; WILLIAMSON, T. (orgs.). Property-owning democracy: Rawls and beyond. Edição Google Play. Malden: Blackwell, 2012, cap. 4.

O’NEILL, M.; WILLIAMSON, T. (orgs.). Property-owning democracy: Rawls and beyond. Edição Google Play. Malden: Blackwell, 2012.

PARIJS, P. van. Difference principles. In: FREEMAN, S. R. (org.). The Cambridge companion to Rawls. Cambridge: Cambridge University Press, 2003, pp. 200-240.

PENNY, R. Incentives, inequality and self-respect. Res Publica, v. 19, n. 4, pp. 335-351, 2013.

QUERALT, J. The place of the market in a Rawlsian economy. Analyse \& Kritik, v. 35, n. 1, pp. 121-140, 2013.

RAWLS, J. Political liberalism. Nova York: Columbia University Press, 1996.

. A theory of justice. 2. ed. Cambridge: Belknap Press, 1999.

. Justice as fairness: A restatement. Cambridge: Belknap Press, 2001.

SCHWEICKART, D. After capitalism. 2. ed. Edição Kindle. Lanham: Rowman \& Littlefield, 2011.

Property-owning democracy or economic democracy? In: O’NEILL; M; WILLIAMSON, T. (orgs.). Property-owning democracy: Rawls and beyond. Edição Google Play. Malden: Blackwell, 2012, cap. 10.

WARD, B. The firm in Illyria: Market syndicalism. American Economic Review, v. 48, n. 4, pp. 566-589, 1958.

WILLIAMS, A. Linguistic protectionism. In: GOSSERIES, A.; VANDERBORGHT, Y. (orgs.). Arguing about justice: Essays for Philippe Van Parijs. Louvain-la-Neuve: Presses Universitaires de Louvain, 2011, pp. 395-402. 